\title{
Robert E. Alvis, Religion and the Rise of Nationalism. A Profile of an East-Central European City
}

Syracuse, Syracuse University Press, 2005, xxvi + 227 p.

\section{André Sleiman}

\section{(2) OpenEdition Journals}

\section{Édition électronique}

URL : http://journals.openedition.org/assr/21086

DOI : $10.4000 /$ assr. 21086

ISSN : $1777-5825$

\section{Éditeur}

Éditions de l'EHESS

\section{Édition imprimée}

Date de publication : 31 décembre 2009

Pagination : 75-342

ISBN : 978-2-7132-2218-4

ISSN : 0335-5985

\section{Référence électronique}

André Sleiman, « Robert E. Alvis, Religion and the Rise of Nationalism. A Profile of an East-Central European City », Archives de sciences sociales des religions [En ligne], 148 | octobre-décembre 2009, document 148-5, mis en ligne le 19 mai 2009, consulté le 21 septembre 2020. URL : http:// journals.openedition.org/assr/21086; DOI : https://doi.org/10.4000/assr.21086 


\title{
Robert E. Alvis, Religion and the Rise of Nationalism. A Profile of an East-Central European City
}

\author{
Syracuse, Syracuse University Press, 2005, xxvi + 227 p.
}

\author{
André Sleiman
}

\section{RÉFÉRENCE}

Robert E. Alvis, Religion and the Rise of Nationalism. A Profile of an East-Central European City, Syracuse, Syracuse University Press, 2005, XXVI +227 p.

1 Le facteur religieux dans le développement du nationalisme est quelque peu mis à l'écart par rapport aux facteurs socio-économiques et politiques, jusque-là jugés plus important par les chercheurs. On s'entend en effet à dire que le nationalisme est grosso modo apparu en Europe au XVIII ${ }^{\mathrm{e}}$-XIX ${ }^{\mathrm{e}}$ siècles, et qu'il était, surtout, laïque de nature, c'est-à-dire reposant sur des composantes telles que la langue, la culture, le passé commun. La genèse de l'idée nationaliste accompagne, bien évidemment, la société moderne naissante: sécularisme et nationalisme sont les produits du siècle des Lumières et du rationalisme. La légitimité de l'État-nation procéderait de la volonté du peuple, abstraction faite de toute sanction religieuse, comme la Révolution française le montre à merveille. Il y a donc une profonde rupture avec la société de l'Ancien régime, laquelle était rigoureusement définie par la hiérarchie des groupes de statut et des droits politiques hérités.

Dans un premier temps, on chercha à expliquer, plusieurs cas à l'appui, la montée des nationalismes par la décrépitude de la pensée et de la pratique religieuses. Dans un second temps, c'est le nationalisme qu'on identifia à la religion : une thèse qui trouve ses prémices dans Les formes élémentaires de la vie religieuse d'Émile Durkheim (1912), où la religion est vue comme un besoin humain d'affirmer et de renforcer des liens de solidarité qui permettent à la société de bien fonctionner. 
3 L'argument de ce livre est que la religion occupa une place essentielle dans le développement de l'idée nationaliste en Pologne, plus particulièrement dans la ville de Poznań, depuis l'invasion prussienne, en 1793, à l'affranchissement de l'empire, en 1848. Parmi les multiples définitions du nationalisme, l'auteur en retient une: un sentiment d'identification avec d'autres membres d'un groupe linguistique et culturel et/ou un sentiment d'allégeance à un système politique partagé ; le nationalisme est, aussi, un sentiment de souveraineté collective sur un territoire habité par des compatriotes (p. xxi). Il fait nécessairement appel à des liens émotionnels parce qu'il se réclame, dans la plupart des cas en Europe centrale et orientale, d'une identité ethnique préexistante ayant quelque fondement concret. Finalement, c'est un phénomène typiquement moderne qui s'accompagne de développements politiques, culturels et socioéconomiques.

4 Poznań, à la fin du xvIII ${ }^{\mathrm{e}}$ siècle, est une ville de taille importante au sein de la République des Deux Nations (fédérant le Royaume de Pologne et le Grand-duché de Lituanie), où la société est campée sur un régime d'étanchéité communautaire, garantissant le fonctionnement ordonné de la cité. La population de la ville est catholique à $60 \%$ (en grande partie d'ethnicité polonaise, mais aussi allemande), et comprend deux minorités non négligeables : les juifs $(25 \%)$ et les protestants (15\%, luthériens et réformés). Ces derniers sont presque tous d'ascendance allemande. Le pouvoir de l'Eglise catholique à Poznań est tel que les valeurs catholiques sont souvent traduites dans la législation. Les non-catholiques sont légalement obligés de montrer du respect à la foi catholique et à la Vierge Marie (p. 16). La sécurité des protestants, très défavorisés juridiquement, est largement tributaire de la bonne volonté des catholiques. Bien que de nombreux protestants excellent dans leurs entreprises économiques, leur contribution à la vie publique et culturelle demeure assez pauvre. Les juifs sont d'un point de vue légal plus chanceux que les protestants : leur activité économique ne se heurte pas à une législation restrictive : si les juifs ont enfreint un ordre sacré, ce n'est pas à une sanction mondaine de les punir, mais à Dieu. Mais leurs activités sont expressément limitées par les notables de la ville. Contrairement à la France et à l'Angleterre, où l'autorité ecclésiale est subordonnée à l'autorité séculière du gouvernement, ce n'est pas le cas dans la RDN. L'idéologie officielle de l'État est le catholicisme, et son ascendant est d'autant plus grand que l'autorité centrale est faible.

5 L'invasion de la Pologne de l'ouest par l'Armée prussienne, en 1793, marque la partition de la République des Deux Nations. Les Polonais catholiques acceptent, avec résignation, l'occupation allemande comme un fait accompli, mais sont confrontés à une économie en détérioration croissante, et surtout à une culture politique et une langue qui leur sont totalement étrangères, ce qui ne fait qu'aiguiser leur sentiment d'aliénation. Conscients du repli des catholiques, et de leur réticence à leur égard, les Prussiens se mettent à la recherche d'autres alliés. Ils commencent à entretenir une coopération avec les juifs, et preuve de bonne foi, leur accordent la citoyenneté prussienne, au grand dam des responsables polonais, qui assistent, impuissants, au rétrécissement de leur autorité. Mais les juifs ne sont pas les seuls à pouvoir contourner les notabilités locales : les plus grands bénéficiaires de la présence prussienne sont les protestants, lesquels se trouvent soudain débarrassés de leur statut inférieur, et ne tardent pas à s'affirmer dans la vie publique avec une audace accrue.

6 Les autorités prussiennes entament très vite une réforme des pratiques protestantes dans la province polonaise de l'Empire. Il s'agit de réinventer le protestantisme local, à 
commencer par le "purifier» de l'influence des pratiques et "superstitions" catholiques. En effet, non seulement le calendrier catholique a longtemps servi de repère aux protestants de Pologne, mais certaines fêtes catholiques sont également respectées et observées par eux. Ces mesures sont d'abord mal reçues par les congrégations protestantes, longtemps autonomes et accoutumées à ne pas rendre compte à quelque autorité centrale. Mais la faiblesse et l'indigence de leurs institutions coupent court à leur résistance face à l'interférence des Prussiens, surtout que ce soupçon s'accorde mal avec leurs croyances religieuses. Dès son installation, la Prusse se fait l'avocat de la tolérance religieuse et garantit à toutes les confessions le libre exercice de la religion. En même temps, l'État se montre sympathique aux intérêts des confessions protestantes, devenues Églises de l'État (p. 113), et maintient avec elles une relation préférentielle par le biais de privilèges informels. La restructuration des institutions protestantes se met en place à travers une assistance financière généreuse et la construction d'un nombre relativement important de bâtiments religieux. Une bienveillance qui n'est pas sans contrepartie: en tant que représentants de l'État, les pasteurs sont censés encourager la population à travailler dur, à obéir aux autorités, et à révérer le roi, leur gouverneur nommé par Dieu (p.114). Vers les années 1830, les protestants de Poznań (entretemps devenue Posen) sont finalement intégrés dans des structures qui s'étendent à travers l'ensemble du royaume prussien (p. 126).

7 Le facteur économique joue un grand rôle dans la transformation profonde de Poznań. $\mathrm{Au}$ XVIII ${ }^{\mathrm{e}}$ siècle, l'économie de la ville est encore largement agraire. Endossant les thèses d'Ernest Gellner dans Nations and Nationalism (1983), l'auteur montre comment la mise en branle d'une économie industrielle favorise l'essor des sentiments nationalistes. Le "progrès » économique n'aurait peut-être pas été déclenché sans la présence des Prussiens, qui entérinent une " politique de grands travaux ", si l'on peut dire, tentant de refaçonner le paysage socioéconomique et culturel selon le modèle allemand. Il va sans dire que cette politique profite essentiellement aux protestants, contribuant ainsi à les conforter davantage dans leurs attitudes pro-prussiennes.

8 R. Alvis affirme que la faiblesse du gouvernement central, avant 1793, est la principale cause de l'absence d'une culture unifiée au sein de la République des Deux Nations, ce qui favorise naturellement les formes de sociabilité et de culture au sein de la communauté religieuse (p. 64). La première priorité de l'Empire prussien est d'intégrer culturellement le territoire nouvellement conquis au reste de la Prusse, par le biais de la mise en place de systèmes unificateurs dans les domaines éducatif, politique, économique et linguistique. Cette campagne de germanisation implique l'inculcation active de "valeurs germaniques", telles que l'obéissance à l'autorité, l'esprit d'économie (entendue comme administration sobre et mesurée des biens) et de productivité (p.65). Concrètement, elle consiste en la construction d'écoles, d'un théâtre municipal (chargé de propager les arts et l'esthétique en vogue dans l'Empire), le financement d'une presse germanisée, et même, parfois, la réglementation des coutumes vestimentaires. Cependant, ce n'est pas assez pour effacer la conscience polonaise de la plupart des catholiques.

9 Pendant ce temps, en Allemagne, se développe l'idée de la germanité telle que préconisée par Herder (1744-1803), pour qui l'identité nationale est une force spirituelle qui anime un peuple. Le genre humain, dit Herder, consiste en de multiples expressions d'un seul ordre divin, et chaque nation possède des caractéristiques uniques et unificatrices, nommément la langue et la culture, ainsi qu'une destinée 
spécifique, qui la distinguent des autres nations. Bien que les Prussiens n'aient aucunement cherché à susciter un nationalisme allemand dans la province polonaise de l'Empire, la tournure, que l'on appellerait aujourd'hui "assimilationniste ", de leur politique culturelle produit l'effet inverse : les idées herderiennes, sitôt arrivées en Pologne, touchent une corde sensible chez les polonais catholiques et suscitent des engagements passionnés vis-à-vis de ce qu'ils conçoivent comme leur culture nationale. Benedict Anderson, dans Imagined Communities (1983), évoque de manière convaincante la place centrale de l'imprimerie et de l'expansion littéraire dans l'épanouissement du sentiment nationalitaire, et c'est exactement ce qui se passe en Pologne : réimpression des manuels de grammaire polonaise, renouveau littéraire qui puise dans la tradition classique, émergence d'une pensée philosophique polonaise, multiplication des périodiques nationalistes. Du côté prussien, on s'efforce de prêcher le dépassement du clivage allemand/polonais au bénéfice d'une seule et même identité prussienne, comprise comme allégeance à la Couronne impériale. Mais ceci ne fait que durcir davantage les ambitions des nationalistes.

Le renouveau culturel des nationalistes polonais ne prend tout son sens qu'au sein d'un cadre religieux, non dénué de spiritualité. La soumission de l'Église à l'État, la nostalgie d'un temps marqué par une hégémonie catholique empreignant la vie publique, poussent de nombreux Polonais éduqués, nés dans une famille catholique, à réconcilier leurs principes nationalistes avec la foi religieuse. Le courant romantique du XIX siècle favorise indéniablement cette exaltation de l' "ancien» héritage chrétien et des valeurs de l'église catholique. La révolte de nationalistes polonais contre la Prusse repose abondamment sur les ressources de l'Église catholique (p. 178). Paradoxalement, l'ère des ardeurs nationalistes voit, souvent, coexister piété et anticléricalisme. De plus, entre l'État prussien et l'Église catholique, cette dernière commande plus l'allégeance des Polonais, malgré quelques intellectuels désenchantés. La nation polonaise et l'Église sont toutes les deux assiégées par « l'occupant", il est donc logique que l'on s'imagine que le destin de l'une soit lié à celui de l'autre. Mais de ce fait, de nombreux Allemands laïques, surtout catholiques, jusque-là sympathiques vis-à-vis de la cause polonaise, se trouvent aliénés par la tournure que prennent les événements (p. 77), pénalisant du même coup une relation autrefois distinguée, comme le démontre la chute des intermariages dans les années 1830-1840.

11 Nul doute que la communautarisation croissante, qui a lieu à Poznań durant la première moitié $\mathrm{du}$ xIX $\mathrm{e}^{\mathrm{e}}$ siècle contribue à creuser inexorablement le fossé entre Polonais catholiques et Allemands protestants, laissant les populations minoritaires, surtout les Allemands catholiques, dans un entre-deux embarrassant. Les allégeances contradictoires des habitants de Poznań éclatent au grand jour en 1848, année marquée par un enthousiasme révolutionnaire qui se manifeste à travers toute l'Europe (période appelée le «Printemps des nations »). La communauté polonaise, enfiévrée par sa lutte pour la « libération de l'oppression », se proclame énergiquement pour l'indépendance, tandis que la population allemande s'exprime avec la même intensité vis-à-vis d'un État allemand unifié. La lutte entre les deux communautés révèle la place centrale de la religion dans ces identités nationales. 